\section{ESTUDO TOPOGRÁFICO E HISTOLÓGICO DO NŌ SINU-ATRIAL, EM OVINOS DA RAÇA CORRIEDALE}

\author{
ANTONIO FERNANDES FILHO \\ Professor Livre-Docente \\ Faculdade de Medicina Veterinária \\ e Zootecnia da USP
}

\section{INTRODUÇÃO E LITERATURA}

O estudo das diferentes particularidades relacionadas à topografia e morfologia do nó sinu-atrial constitui, ainda hoje, inesgotável campo de pesquisa, face à importância e complexidade desta estrutura.

Trabalhos pertinentes ao focado assunto têm sido, de há muito, o objetivo de vários docentes do Departamento de Cirurgia e Obstetrícia da Faculdade de Medicina Veterinária e Zootecnia da Universidade de São Paulo, visando ampliar os conhecimentos sobre a formação, descoberta por KEITH e FLACK 9 (1907).

Agora, propomo-nos estudar a topografia e os aspectos microscópicos do nó sinu-atrial, em ovinos da raça Corriedale.

Compulsando literatura especializada ao nosso alcan-

FERNANDES FILHO, A. Estudo topográfico e histológico do nó sinu-atrial, em ovinos da raça Corriedale. Rev. Fac. Med. vet. Zootec. Univ. S. Paulo, 17(1/2): 33-36, 1980.

RESUMO: A topografia e a morfologia microscópica do nó sinuatrial, foram estudadas em carneiros da raça Corriadale pelo métodos histológicos. Esta estrutura está localizada no sulco terminal e ângulo diedro formado pela junção da veia cava cranial com o átrio direito. As características morfológicas das células especializadas do nó, bem como os diferentes tipos de fibras que compõe o estroma conjuntivo, foram examinados.

O glicogênio é abundante no citoplasma das células especializadas do nó.

UNITERMOS: Histologia, ovinos*; Coração, nó sinu-atrial * ce, encontramos em PACE1 5, 16, 17 (1919, 1922, 1924) que, esclarece estar o nó sinu-atrial, no homem e nos mamíferos, fazendo parte da parede da veia cava superior e, por um bom trato corresponde exatamente ao sulcus terminalis. Evidencia, em um cordeiro, no trato da desembocadura da veia cava cranial, em frente ao nó de KEITH e FLACK, na parede desta veia, a presença de outro espessamento de fibras nodais, o qual interpretou como um segundo nó sinusal.

CHIODI $^{3}$ (1932) pesquisando a topografia do tecido nodal específico, nos ovinos, descreve que ele se apresenta com os dois ramos separados, formando-se duas massas distintas (direita e esquerda). A parte direita deste tecido está
Trabalho apresentado à XXXII Conferência Anual da Sociedade Paulista de Medicina Veterinária, realizada em Pirassununga, São Paulo, de 06 a 09 de setembro de 1977 e ao V Congresso Panamericano de Anatomia, realizado em São Paulo, de 02 a 07 de julho de 1978. representada por fibras com direção transversal, delgadas, onduladas e com estrias transversais menos evidentes que no resto do miocárdio. Uma expansão da parte direita com fibras paralelas, sempre finas, onduladas e com estrias transversais menos evidentes que no resto do miocárdio. Uma expansão da parte direita projeta-se para a esquerda, confundindo-se com o feixe de PAPEZ. Na parte mais alta do septo interatrial o tecido miocárdico adquire disposição prexiforme, tornando-se particularmente evidente em um especial estrato subendocárdico do átrio esquerdo. Este estrato mostra bainha conjuntiva, forma par de pregas, de modo que, observado com pequeno aumento, lembra as circunvoluções cerebrais.

GLOMSET e GLOMSET8 (1940), estudando, macro e microscopicamente a região do nó sinu-atrial no homem, cão, boi, cameiro, porco e cavalo, dizem que o citado nó se mostra como segmento de lâmina muscular cobrindo a primeira parte da veia cava superior e se expande à esquerda, para formar o miocárdio atrial.

COPENHAVER e TRUEX ${ }^{4}$ (1952), examinando o sistema de condução, no homem, carneiro e macaco, mediante cortes histológicos seriados, registram, para o carneiro, que o nó sinu-atrial é identificado na junção da veia cava superior e átrio direito. As fibras nodais são estreitas, com menos miofibrilas e o arranjo é mais irregular, exibindo-se feixes envolvidos por considerável quantidade de tecido conjutivo. Próximo ao centro da área do tecido específico, encontram com certo destaque, a artéria nodal. No tecido conjuntivo, há numerosos gânglios e feixes de fibras nervosas.

MEYLING e TER BORG 14 (1957), pesquisando o nó sinu-atrial em ungulados, informam, genericamente, que o tecido nodal se localiza no sulco terminal, possuindo um ramo lateral e outro medial.

BORTOLAMI e PALMIERI'1 (1962), cuidando do nó sinu-atrial em cameiros, jovens e adultos, identificam-no, nos animais jovens, a $1 \mathrm{~mm}$ da desembocadura da veia cava cranial no átrio, a ocupar todo o sulco terminal e, portan- 
to, ultrapassando-o no sentido anteromedial, enquanto nos adultos, o aludido nó está localizado na espessura da musculatura da veia cava cranial e sulco terminal, permanecendo sempre do lado direito da junção cavo-atrial.

TRUEX e SMYTHE18 (1965) relatam que discreta massa de fibras pode, usualmente, ser interpretada como o marca-passo, na junção da veia cava superior e átrio direito, nos corações da maioria dos mamíferos. Uma grande, ou várias, pequenas artérias nodais são comumente circundadas por rede anastomótica composta de estreitas fibras nodais estriadas.

Ainda, no atinente aos dados relativos à morfologia e topografia do nó sinu-atrial, buscamos informações também nos Compêndios de Anatomia Veterinária, expondo-se a seguir:

MANNU1 2 (1930) revela que o nó sinu-atrial, nos ruminantes, é constituido por feixes de fibras musculares pálidas, dispostas em rede, entre as margens da veia cava cranial e o átrio direito, ao nível ou nas proximidades do sulco terminal. Suas fibras irradiam-se em várias regiōes, isto é, um feixe sobe ao longo da veia cava cranial, entre a parede direita e a anterior; um feixe lateral (direito) expande-se sobre a superfície externa do átrio e, um feixe medial (esquerdo) apoia-se sobre o sulco interatrial.

FAVILLI6, 7 (1931, 1943) descreve que o sistema sino-auricular, no homem e nos ruminantes, é formado por fibras musculares pálidas, dispostas em rede, entre as margens das veias cavas e o átrio direito, ao nivel e nas vizinhanças do sulco terminal.

ELLENBERGER e BAUM 5 (1932) declaram que, nos ruminantes, encontra-se, no sinus venosus, sistema muscular de estrutura reticular e específica, disposto em forma de fita em "V". O ápice desta fita, que corresponde ao nó sinusal, do homem, localiza-se na parede anterior da região limítrofe entre a veia cava cranial e a aurícula direita, enquanto seus ramos (um direito e outro esquerdo) dirigem-se caudalmente e para baixo na região lateral das veias cavas e dos átrios.

MARTIN e SCHAUDER 13 (1938) registram, para bovinos e ovinos, na região do nó sinusal, entre a veia cava cranial e o átrio direito, a presença de peculiar fita muscular, cujo ápice se encontra na parede anterior desta área limítrofe, enquanto os ramos dirigem-se caudoventralmente para as paredes laterais do átrio e da veia cava.

BRUNI e ZIMMERL ${ }^{2}$ (1947) relatam que o nó sinuatrial é identificável nos cortes histológicos da região da desembocadura da veia cava cranial, nos ruminantes.

\section{MATERIAL E MÉTODO}

Nossa investigação esteia-se no exame de 12 corações retirados de carneiros da raça Corriedale, machos, adultos, provenientes de várias zonas de criação do Estado do Rio Grande do Sul e abatidos no Instituto Butantã de São Paulo.

Utilizamos para o estudo da topografia do nó sinuatrial, 6 órgãos e, deles separamos fragmentos seriados com aproximadamente $0,5 \mathrm{~m} \mathrm{~cm}$ de largura que abrangiam toda a extensão da desembocadura da veia cava cranial. Estes, fixamo-los em líquido de Bouin durante 24 horas e, após técnica usual, procedemos à sua inclusão em parafina, obtendo-se depois, da porção inicial de cada fragmento, cortes de $5 \mathrm{~F}$, posteriormente corados pelos métodos da hematoxilina eosina e tricrômico de Mallory.

Com o objetivo de verificar os diferentes aspectos morfológicos do citado nó, bem como pesquisar a presença de glicogênio, recolhemos fragmentos com as mesmas di- mensões, do terço médio do sulco terminal de 6 outros corações. Assim parte deste material, o isolado de 3 animais, fixamos durante 24 horas em líquido de Bouin e depois de técnica usual e inclusão em parafina obtivemos corte de 5 $\mu$, corados a seguir pelos métodos da hematoxilina eosina, tricrômico de Mallory, hematoxilina férrica de Heidenhein, Gordon e aldeído-fucsina de Gomori. Fixamos os fragmen. tos pertencentes aos outros 3 órgãos, em líquido de GENDRE a $4{ }^{\circ} \mathrm{C}$ durante 24 horas e, após o preparo devido, incluimo-los em parafina, para, finalmente, conseguir cortes de $5 \mu$, que submetemos ao método do ácido periódico de SCHIFF (PAS) antes (McMANNUS, 11 1946) e após a ação da amilase salivar (LISON, ${ }^{0} 1960$ ).

Para a documentação utilizamos fotomicrografias dos cortes histológicos.

\section{RESULTADOS}

Os cortes histológicos obtidos das porçoes iniciais dos fragmentos seriados da junção da veia cava cranial com o átrio direito, submetidos aos métodos de H.E. e tricrômico de Mallory, mostram o tecido nodal localizado no território correspondente ao sulco terminal e ângulo diedro cavoatrial.

As células desse tecido, observadas em preparações coradas pelos métodos de H.E. e hematoxilina férrica de Heidenhein (Fig. 1), apresentam núcleo único ou duplo, de forma arredondada ou ovóide, circundado por halo claro, provido de cromatina frouxa e nucleólo nítido. O citoplasma, acidófilo, exibe miofribilas sinuosas, com estriações transversais, em número inferior ao encontrado no miocárdio comum, ocorrendo o inverso em relação ao glicogênio, identificado, com maior abundância, no tecido nodal, pelo método PAS antes e após a ação da amilase salivar.

Já, o tecido conjuntivo, visto ao redor dessas células com auxílio dos métodos de H.E., tricrômico de Mallory, aldeido-fuesina de Gomori e Gordon, revela-se constituído de fibras colágenas, elásticas e reticulares, estas aparecendo em menor quantidade.

Ainda, identificamos, a acompanhar o tecido nodal, artérias de pequeno e médio calibres, bem como veias e nervos; por outro lado, evidenciamos a presença de gânglios nervosos, apenas em posição posta à do aludido nó.

\section{COMENTÁRIOS}

O estudo da topografia do nó sinu-atrial, em carneiros da raça Corriedadle, consitutui, sem dúvida, a base indispensável para a investigação relativa ao suprimento sanguíneo do aludido nó. A localização deste tecido, pesquisamola histologicamente, examinando as regiōes da desembocadura da veia cava cranial junto ao átrio direito e ao septo interatrial. Assim, as técnicas utilizadas permitiram identificar o tecido nodal na junção da veia cava cranial com o átrio direito, em correspondência ao sulco terminal e ângulo diedro cavo-atrial. Os achados obtidos, nesta raça, coincidem, parcialmente, com os registrados por BORTOLAMI e PALMIERI ${ }^{1}$, BRUNI e ZIMMERL $^{2}$, COPENHAVER e TRUEX ${ }^{4}$, ELLENBERGER e BAUM ${ }^{5}$, FAVILLI 6,7 , MANNU I' 2 , MARTIN e SCHAUDER 13 , MEYLING e TER BORG 14 , TRUEX e SMYTHE 18 , uma vez 'que alguns destes AA. informam, genericamente, estar o tecido nodal na junção da veia cava cranial com o átrio direito (BRUNI e ZIMMERL ${ }^{2}$, COPENHAVER e TRUEX ${ }^{4}$, ELLENBERG e $^{2}$ BAUM $^{5}$, MARTIN e SCHAUDER ${ }^{13}$, TRUEX SMYTHE ${ }^{18}$ ), 
apenas no sulco terminal (BORTOLAMI e PALMIERI ${ }^{l}$ ovinos, adultos, MEYLING e TER BORG 14 ) ou, ainda, nesta região e nas suas proximidades. (BORTOLAMI e PALMIERI' - ovinos jovens, FAVILLI6,7. MANNU1 2). Ressalte-se, de outra parte, que GLOMSET e GLOMSET 8 , relativamente à posição do mencionado nó, indicam-no situado na primeira parte da veia cava superior, enquanto PACE $15,16,17$ e CHIODI ${ }^{3}$ caracterizam-no como formado por duas massas distintas, uma à direita e outra a esquerda da desembocadura da veia cava cranial, disposições estas não evidenciadas por nós em espécimes da raça Corriedale.

Já, relativamente à morfologia do nó sinu-atrial, segundo verificamos, as células apresentam núcleo circundado por halo claro, de forma arredondada ou oval, com cromatina frouxa e nucleólos nítidos, enquanto o citoplasma mostra-se acidófilo e rico em glicogênio com miofribilas escassas em relação ao miocárdio atrial.

Estes dados, obtidos em carneiros da raça Corriedale coincidem parcialmente com as informações exaradas por AA. que tratam do assunto genericamente em mamíferos (TRUEX e SMITHE ${ }^{18}$ ) ou em ruminantes (ELLENBER. BER e BAUM 5 , FAVILLI6, 7 , MANNU ${ }^{12}$ ) ou, ainda, com aqueles que consideram particularmente os ovinos (CHIODI ${ }^{3}$ ), em especial com a descrição de COPENHAVER e TRUEX ${ }^{4}$, que registram, na região nodal, a presença de fibras estreitas, de arranjo irregular, envolvidas por considerável quantidade de tecido conjuntivo, formando complexa rede em cujo centro evidenciam a artéria nodal, sendo vistos numerosos gânglios e feixes de fibras nervosas no tecido conjuntivo.

\section{CONCLUSÕES}

Com base nas observações realizadas em 12 corações de ovinos da raça Corriedale, adultos, machos, chegamos às seguintes conclusర̃es:

1. o nó sinu-atrial encontra-se, nestes animais, localizado na junção da veia cava cranial com o átrio direito, mais exatamente, em correspondência ao sulco terminal e ângulo diedro cavo-atrial;

2. as células do tecido nodal caracterizam-se por apresentarem núcleo único ou duplo de forma arredondada ou ovóide, circundado por halo claro com cro. matina frouxa e nucleólo nítido, citoplasma acidófilo no qual observamos poucas miofibrilas sinuosas com estriaçőes transversais. Estas células acham-se envolvidas por grande quantidade de tecido conjuntivo onde predominam fibras colágenas e elásticas. Artérias de pequeno e médio calibres, veias e nervos acompanham a formação nodal, enquanto gânglios nervosos são vistos localizados, mais comumente, na face auricular da desembocadura da veia cava cranial;

3. as células que constituem o tecido nodal diferem, ainda, daquelas que integram o miocárdio atrial, por apresentarem no citoplasma maior quantidade de glicogênio.
FERNANDES FILHO, A. Topographic and histological study of the sinus node in Corriedale sheep. Rev. Fac. Med. vet. Zootec. Univ. S. Paulo, 17(1/2): 33-36, 1980.

SUMMARY: The topography and the microscopic morphology of the sinus node were studied in Corriedale sheep by histological methods. This structure is located at the sulcus terminalis and at the dihedral angle formed by the junction of the cranial caval vein with the right atrium.

The morphological characteristics of the specialized cells of the node, as well as the different type of fibers that compose the connective stroma are examined. Glycogen is abundant in the cytoplasm of the specialized cells of the node.

UNITERMS: Histology, sheep * Heart, sinus node *

\section{FIGURA 1}

Fotomicrografias de cortes transversais do terço médio do sulco terminal, de ovinos adultos, machos, da raça Corriedale, mostrando o miocárdio atrial $(\mathrm{A}-\mathrm{B})$ e o tecido nodal $(\mathrm{C}-\mathrm{D})$. Método da hematoxilina férrica de Heidenhein A e D $\pm 400 x$ B e C $\pm 160 x$

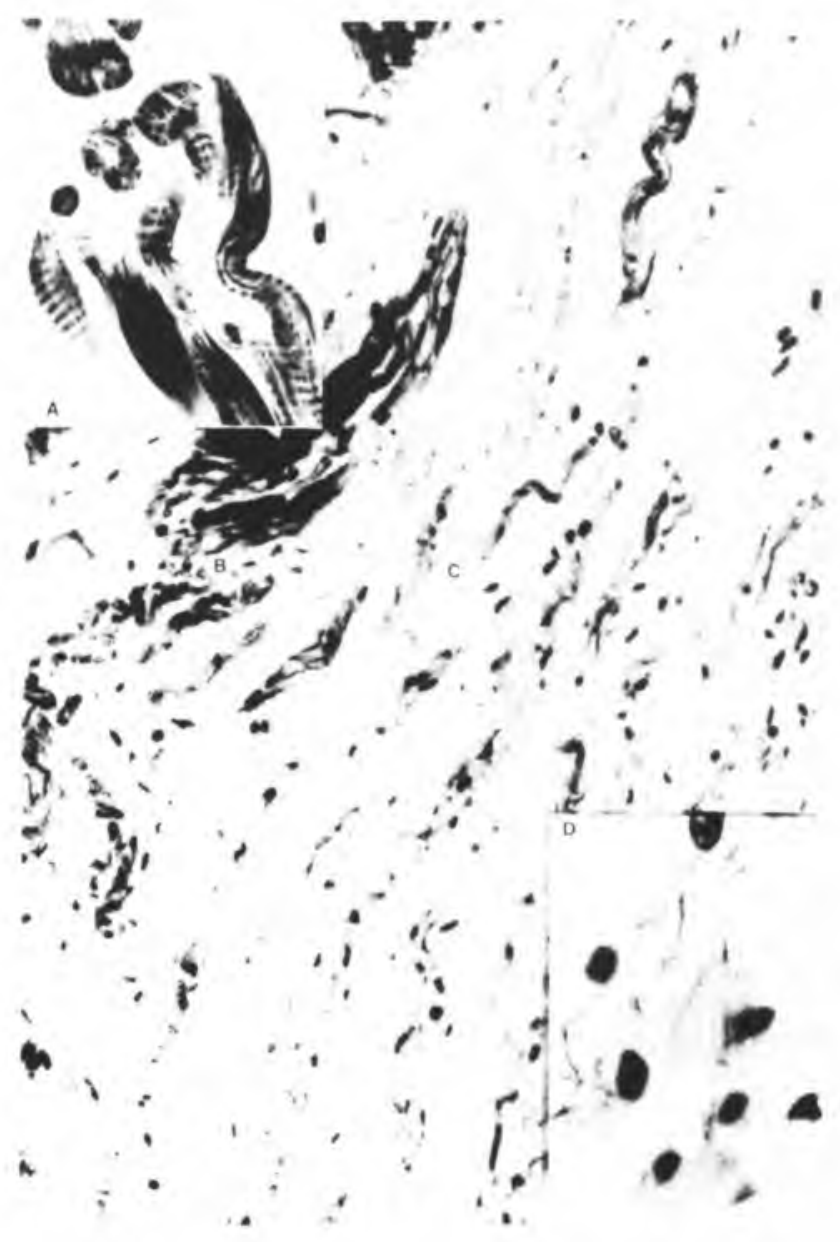




\section{REFERENCIAS BIBLIOGRĀFICAS}

1 - R. BORTOLAMI \& PALMIERI, G. Osservazione sul nodo del seno di Ovis aries, Capra hircus, Bos taurus ed Equus caballus. Riv. Biol., Perugia, 55: $281-319,1962$.

2 - BRUNI, A.C. \& ZIMMERL, U. Anatomia degli animali domestici, Milano, Francesco Vallardi, 1957. v. 2, p. 297-8.

3 - CHIODI, V. Il nodo seno-atriale del cuore dei mammiferi. Clin. Vet., Milano, 55: 689-728, 1932.

4 - COPENHAVER, W.M. \& TRUEX, R.C. Histology of the cardiac conduction system in man and other mammals. Anat. Rec., Philadelphia, 114: 601$25,1952$.

5 - ELLENBERGER, W. \& BAUM, H. Handbuch der Vergleichenden Anatomie der Haustiere. 17 Auf. Berlin, Julius Springer, 1932. p. 629.

6 - FAVILLI. N. Nozioni comparate di anatomia e fisiologia degli animali rurali. Torino, Unione Tipografico-- Editrice Torinese, 1931. p. 388-9.

7 - FAVILLI, N. Nozioni comparate di anatomia e fisiologia degli animali agricoli. Milano, Francesco Vallardi, 1943. p. $396-7$.

8 - GLOMSET, D.J. \& GLOMSET, A.T.A. A morphologic study of the cardiac conduction system in ungulates, dog and man. I. The sino-atrial node. Amer. Heart J., St. Louis, Mo., 20: 389-98, 1940.

9 - KEITH, A. \& FLACK, M. The form and nature of the muscular connections between the primary divisions of the vertebrate heart. J. Anat. Physiol., London, 42: 172-89, 1907.
10 - LISON, L. Histochimie et cytochimie animals. Paris, Gauthier Villars, 1960. v. 2, p. 432-4.

11 - McMANUS, J. F. A. Histological demonstration of mucin after periodic acid. Nature, London, 158 (4006): 202, 1946.

12 - MANNU, A. Apparechio vascolare. In: ZIMMERL, V. Trattato di anatomia veterinaria. Milano. Francesco Vallardi, 1930. v. 2, p. 24.

13 - MARTIN, P. \& SCHAUDER, W. Lehrbuch der Anetomie der Haustiere. 3 Auf. Stuttgart, Schickhardt e Ebner, 1938. v. 3, t. 3, p. 383-4.

14 - MEYLING, H. A. \& TER BORG, H. The conducting system of the heart in hoofed animals. Cornell Vet., Ithaca, 47: 419-55, 1957.

15 - PACE, D. Nuove richerche sul tessuto specifico del cuore dell'uomo e dei mammiferi. I. Nota. Atti R. Accad. med. chir., Napoli, 73, 1919.

16 - PACE, D. Nuove ricerche e considerazioni sul nodo del seno del cuore dei mammiferi. Rif. med., Napoli, 38: 385-9, 1922.

17 - PACE, D. Dix années de recherches sur le tissu spécifique du coeur. Arch. Mal. Coeur, Paris, 17: 193--207, 1924.

18 - TRUEX, R. C \& SMYTHE, M. Q. Comparative morphology of the cardiac conduction tissue in animals. Ann. N.Y. Acad. Sci., New York, 127:19$33,1965$.

Recebido para publicação em: 11/04/1980 Aprovado para publicação em: 20/10/1980 